\title{
Transformation of Patient's EEG Oscillators into Music-Like Signals for Correction of Stress-Induced Functional States
}

DOI: 10.17691/stm2016.8.1.12

Received April 6, 2015

A.I. Fedotchev, DSc, Leading Researcher, Laboratory of Reception Mechanisms";

A.T. Bondar, PhD, Senior Researcher, Laboratory of Reception Mechanisms";

A.V. Bakhchina, PhD, Senior Teacher, Department of Psychophysiology2;

V.N. Grigorieva, MD, DSc, Head of the Department of Neurology, Neurosurgery and Medical Genetics ${ }^{3}$.

A.A. Katayev, Student, Department of Psychophysiology2;

S.B. Parin, DSc, Head of the Laboratory of Psychophysiology2;

G.S. Radchenko, PhD Student, Department of Psychophysiology2;

S.A. Polevaya, DSc, Head of the Department of Psychophysiology2; Head of the Department of Neurophysiology and Experimental Modeling of the Central Research Laboratory ${ }^{3}$

IInstitute of Cell Biophysics, Russian Academy of Sciences, 3 Institutskaya St., Pushchino, Moscow Region, 142290, Russian Federation;

2Lobachevsky State University of Nizhni Novgorod, 23 Prospekt Gagarina, Nizhny Novgorod, 603950,

Russian Federation;

${ }^{3}$ Nizhny Novgorod State Medical Academy, 10/1 Minin and Pozharsky Square, Nizhny Novgorod, 603005,

Russian Federation

The aim of the investigation was to compare efficacy of three variants of musical neurobiocontrol technology, involving transformation of the current values of the patient's EEG oscillators into music-like signals in correcting stress-induced functional state.

Materials and Methods. 15 volunteers, being in the stress condition, were subject to three examinations. In the first one the examinees were presented music-like signals, resembling the sounds of a flute by its timbre, which were smoothly varying in pitch and intensity in direct relation to the current amplitude of the spectral component of EEG - EEG oscillator - dominating in the subject. In two other examinations the same transformations of EEG were supplemented by the introduction of musical elements: rhythm and beat. Objective (shifts of EEG-alpha rhythm intensity relative to the background) and subjective (results of all tests before and after the exposure) criteria of efficacy were used in the study.

Results. Under the influence of therapeutic procedures the increase of EEG-alpha rhythm intensity against the background was noted, accompanied by the growth of health and mood indicators, reduction of emotional disadaptation degree and the level of stressedness in the examined persons. The most prominent effects were revealed when presented sound signals were structured, especially by introducing $1 \mathrm{~Hz}$ rhythm in them.

Conclusion. Transformation of the current values of patient's EEG oscillators into music-like signals is supposed to be a perspective way of improving the efficacy of biocontrol procedures in correcting various functional disorders.

Key words: neurobiocontrol; EEG oscillators; transformation of EEG into music-like signals; correction of functional disorders.

Presently, ideas of preventive medicine find more understanding in the society, as the main task of this discipline is not to treat diseases but to reveal changes in the organism of a practically healthy person which may lead to illnesses, and to take target measures to prevent them [1]. People today have to confront various extreme situations, terroristic acts, armed conflicts and to be exposed to continuous stresses - occupational, social, psychoemotional, and so on [2]. Stress as a chronic psychophysiologic overstrain may provoke manifestation or exacerbation of disease symptoms, be one of the risk factors or aggravate the severity of its course. Every-day psychic stress is a cause of multiple widely-spread serious diseases, including hypertension, strokes, infarctions, oncopathology and others [3]. All the above said makes vital the development of technologies, timely eliminating stressinduced functional disorders [4] and creating personified methods of cognitive rehabilitation [5].

In recent decades a field of medical investigations called "brain-computer interface" $(\mathrm{BCl})$ has been formed and is rapidly evolving. It provides a man with the opportunity to translate his psychic efforts into specific electroencephalogram (EEG) patterns to control technical devices and communication with the external environment directly from the brain not involving peripheral nerves and muscles [6]. A special branch of $\mathrm{BCl}$ is neurobiocontrol (NBC), which does not imply a direct control of external devices, but an intentional usage of the outer feedback for modulation of a physiological

For contacts: Aleksandr I. Fedotchev, e-mail: fedotchev@mail.ru 
signal inherent to the brain [7]. Though $\mathrm{BCl}$ and $\mathrm{NBC}$ are widely used in the correction of diverse functional disorders, insufficient controlled studies to elucidate the fundamentals [8] and to improve the efficacy of these approaches [9] have been noted in recent reviews.

Previously an original technology of musical NBC was presented by us. It uses musical effects, controlled by relevant bioelectrical characteristics of individual's brain - EEG oscillators - on the basis of a feedback concept [10]. Positive results obtained by experimental testing of this technology, allowed us to draw the conclusion on the perspectiveness of using musical feedback from EEG subject in the correction of stress-induced functional disorders. However, this investigation helped us to reveal two limitations of applied technology. Firstly, it used interruptions of music as an informational feedback signal, which may lead to the negative emotional reactions and make the NBC process somewhat difficult. Secondly, the technology used the preselected musical compositions, i.e. the task of selecting music for each examined individual was not solved. This aspect seems to be especially important, since only presenting music in accordance with the patient's brain rhythms may give marked therapeutic effects via involvement of synchronization and plasticity mechanisms [11].

The present work is directed to overcoming the abovementioned limitations of NBC technology and improving its efficacy. For this, instead of interrupted classical music we used music-like signals, produced by on-line transformation of EEG oscillator current values into feedback signals, resembling the sounds of a flute. In one case, these sound signals were smoothly varying in pitch and intensity in direct relation to the current amplitude of EEG oscillator. In two other cases the flute sound variations were supplemented by the introduction of musical elements - rhythm and beat. Experimental testing of the described technology implementation variants was carried out on the same examined persons using objective (shifts of EEG-alpha rhythm intensity relative to the background) and subjective (results of all tests before and after the exposure) criteria.

The aim of the investigation was to compare efficacy of three variants of transforming current values of the patient's EEG oscillators into music-like signals in correcting stress-induced functional disorders.

Materials and Methods. The study involved 15 workers of the Institute of Cell Biophysics, Russian Academy of Sciences (Pushchino, Moscow Region), aged 23-55 years, who addressed the specialists of the psychological release office complaining of psychoemotional strain and stress, and volunteered to participate in three examinations.

The work was performed in accordance with ethical principles established by European Convention for the Protection of Vertebrata used for Experimental and other Scientific Purposes (the Convention was passed in Strasburg, March, 18, 1986, adopted in Strasburg, June, 15, 2006) and approved by Ethics Committee of the Institute of Cell Biophysics, Russian Academy of
Sciences. Written informed consent was received from every examined person.

At the beginning of every three examinations psychophysiological condition of every examined individual was assessed by means of three tests:

HAM test, in which the participants evaluate their present health, activity and mood [12];

EDL test, determining the present level of emotional disadaptation [13];

SL test, a modified EDL test, developed by the authors, which assesses stressedness level; this test uses adjectives describing the level of stress instead of the adjectives characterizing the degree of emotional disadaptation.

After initial testing, EEG sensors (active electrode in $\mathrm{Cz}$ lead, reference and ground - on ear lobules) and earphones (0-40 dB sound level, $100-2,000 \mathrm{~Hz}$ frequency range) were placed. The participants were asked to sit quietly with their eyes closed during the whole procedure and to "listen" to the work of their brain. Then 30-second background EEG was recorded during which the dominating narrow-band $(0.4-0.6 \mathrm{~Hz})$ spectral component in the range of EEG-alpha rhythm $(8-13 \mathrm{~Hz})$ was determined for each examined person, using original modification of dynamic spectral analysis, based on the fast Fourier transform [14].

Once the background was recorded, an operating mode was switched on for $10 \mathrm{~min}$, during which the current amplitude of the revealed EEG oscillator was being transformed into music-like signals with the timbre resembling the sounds of a flute. In the first examination these sound signals smoothly varied in pitch and intensity in accordance with the current EEG oscillator amplitude ("Flute" series). In two other examinations variations of sound signals in pitch and intensity were supplemented by the introduction of musical elements: rhythm and beat. When rhythm was introduced, smooth variations of flute sounds were heard on the background of weak clicks, given with $1 \mathrm{~Hz}$ frequency ("Rhythm" series). In case of beat introduction, flute sounds were presented with a pitch height varying in a jump-wise manner -1 per second ("Beat" series).

At the end of each examination the examined persons were questioned about their feelings and effects, and underwent HAM, ELD and SL tests. The results were statistically processed using Origin 6.0 program package. Mean values (M), standard errors $(m)$ and Student's $\mathrm{t}$-criterion were calculated.

Results and Discussion. To evaluate the EEGeffects of the correction procedures, the numbers of people, demonstrating the increase of EEG-alpha rhythm intensity relative to the initial background were determined in each of the three series of the experiments.

All three variants of the given technology were found to result in positive shifts of EEG-alpha rhythm intensity relative to the background. The greatest effect was registered in the "Rhythm" series, where the gain of EEG-alpha rhythm intensity was noted in $93 \%$ (in 14 out of 15) cases. The respective values for "Beat" and "Flute" series amounted to $73 \%$ (11 out of 15 ) and 60\% (9 out 
of 15). It is important to underline, that in the "Rhythm" series the gain of EEG-alpha rhythm intensity preserved after the procedure. In "Beat" and "Flute" series the increase of EEG intensity relative to the initial level after the procedure was noted rarer: in $40 \%$ (in 6 out 15) and $33 \%$ (in 5 out 15 ) cases, respectively.

Indices of HAM, ELD and SL tests, registered before and after each exposure, were analyzed in order to compare the changes in psychophysiological state of the examined persons under the influence of the procedures for each series of the experiments (See the Table).

It is seen, that almost in all cases positive shifts of the indices relative to the initial level are observed after the procedures. Exceptions are the results of activity level assessment, which are slightly decreasing relative to the initial values in the "Beat" and "Flute" series. Significant positive shifts of indices are recorded only in the "Rhythm" series, where the values of health and mood statistically significantly increased, while the level of disadaptation significantly reduced.

Questioning of the examined persons about their subjective feelings during therapeutic procedures revealed individual reactions to the presented unusual sounds. It referred most of all to the "Flute" series, where sounds varying in pitch and intensity evoked in many participants peculiar ambiguous sensations - from orienting responses and suspicion to bright emotional impressions. It should be noted, that such multidirectional individual reactions to the presented sounds were reflected in the form of maximal standard errors of the means of all indices in the "Flute" series after the exposure (See the Table). Meanwhile, the majority of the examined people commented that structured sound signals in the "Beat" and "Rhythm" series increased their "musicality" and positive perception.

Thus, music-like effects obtained by direct transformation of the subject's EEG into the flute sounds increased the intensity of EEG-alpha rhythm relative to the background, accompanied by positive shifts in the indices of health and mood (HAM test), the degree of emotional disadaptation (EDL test) and the level of stressedness (SL test). The effects were most prominent, when presented sound signals were structured, i.e. when rhythm and beat were introduced in them increasing their "musicality" and positive perception. $1 \mathrm{~Hz}$ rhythm appeared to be especially effective, as the gain of EEG-alpha rhythm intensity lasted, as a rule, even after the procedure, and positive shifts in the assessment of health, mood and emotional disadaptation level reached the level of significance.

According to the modern concepts, EEG-alpha oscillations play an active role in cognitive processes and state self-regulation, demonstrating a strong frequencydependent character. Therefore, any strategies of neuronal activation with the help of NBC must consider individual frequency characteristics of EEG [15]. Exactly this is stipulated in our investigation, where narrow-frequency spectral components of individual's biopotentials - EEG-alpha oscillators - functionally essential for him are subject to direct transformations.

The fact, that patient's EEG oscillators are transformed into the music-like signals is an important aspect of the given investigation. Music is known to be a universal attribute of the human society, capable to evoke strong emotions, change the mood and help to treat psychiatric and neurological diseases [16]. Acting upon the main functions of the body, music possesses the ability "to express inexpressible" [17] and promotes psychophysiological recovery after stress [18]. Therefore, data on the increase of EEG-alpha rhythm intensity, accompanied by positive shifts in psychophysiological characteristics may indicate the formation of so-called "alpha state" as the result of music-like sounds [19], which is characterized by general relaxation without any signs of stress, apprehension and depression.

The three tests evaluating the changes of indices after each procedure demonstrated consistent results, which enabled us to reveal tiny differences of the three variants of the technology used. So, after presenting sounds of a flute smoothly varying in pitch and intensity and causing multidirectional reactions, all indices were characterized by maximal standard errors of the mean values, while positive shifts of psychophysiological indices were minimal. Structuring presented sound signals, which increase their "musicality", was reflected

\begin{tabular}{|c|c|c|c|c|c|c|}
\hline \multirow{3}{*}{ Test indices } & \multicolumn{6}{|c|}{ Series } \\
\hline & \multicolumn{2}{|c|}{ "Flute" } & \multicolumn{2}{|c|}{ "Rhythm" } & \multicolumn{2}{|c|}{ "Beat" } \\
\hline & Before & After & Before & After & Before & After \\
\hline HAM — health & $49.4 \pm 1.4$ & $49.8 \pm 2.1$ & $49.0 \pm 1.3$ & $52.7 \pm 1.3$ & $49.2 \pm 1.3$ & $50.7 \pm 1.4$ \\
\hline HAM — activity & $44.8 \pm 1.2$ & $44.3 \pm 1.6$ & $45.1 \pm 1.3$ & $47.7 \pm 1.5$ & $45.0 \pm 1.4$ & $44.4 \pm 1.5$ \\
\hline HAM - mood & $50.1 \pm 1.4$ & $50.9 \pm 1.8$ & $49.7 \pm 1.3$ & $53.1 \pm 1.2$ & $49.8 \pm 1.2$ & $50.9 \pm 1.4$ \\
\hline EDL - emotional disadaptation & $1.7 \pm 0.2$ & $1.4 \pm 0.3$ & $1.7 \pm 0.2$ & $1.1 \pm 0.1$ & $1.5 \pm 0.3$ & $1.0 \pm 0.2$ \\
\hline SL — stress & $1.0 \pm 0.2$ & $0.7 \pm 0.3$ & $1.1 \pm 0.2$ & $0.6 \pm 0.2$ & $1.1 \pm 0.2$ & $0.7 \pm 0.3$ \\
\hline
\end{tabular}

$\mathrm{N}$ o t e. Compared pairs of values with significance level of $\mathrm{p}<0.05$ are printed in bold type. 
in positive shifts of all indices, especially when rhythm was introduced. The latter is in agreement with the literature data, i.e. cortical rhythms can adapt to structured acoustical signals resulting in selective augmentation of neural responses to the rhythmical effects at the stimulation frequency [20].

It should me mentioned, that the findings of this study, though preliminary and demanding further analysis, meet all present requirements for the controlled experiments [21]. Although the experimental conditions were completely identical, presence or absence of the investigated factor - introduction of the rhythm and beat to the music-like sound signals - was the only difference of the three examinations of the same persons.

Just as in the previously conducted study [10], the basis of the observed effects was interaction of musiclike stimuli with the important bioelectrical activity characteristics of the individual's brain, creating optimal conditions for involvement of adaptation and resonance mechanisms of the central nervous system in the complex body reactions to the action of low-intensity factors of the environment.

Conclusion. Transformation of the current values of patient's EEG oscillators into music-like signals is supposed to be a perspective way of improving the efficacy of biocontrol procedures performed for the correction of stress-induced functional disorders.

Study Funding. The work was supported by the Russian Humanitarian Science Foundation, grants No.16-06-00133, No.14-36-01024 and No.15-06-10894.

Conflicts of Interest. The authors declare no conflicts of interest related to this study.

\section{References}

1. Poletaev A.B., Grinko O.V. Preventive medicine: introduction to the problem. Terra Medica 2012; 4: 4-8.

2. Ushakov I.B., Bubeev Yu.A., Kvasovets S.V., Ivanov A.V. Radiation physiology of higher nervous activity: results and perspectives. Rossiyskiy fiziologicheskiy zhurnal im. I.M. Sechenova 2012; 98(1): 83-94.

3. Runova E.V., Grigoreva V.N., Bakhchina A.V., Parin S.B., Shishalov I.S., Kozhevnikov V.V., Nekrasova M.M., Karatushina D.I., Grigoreva K.A., Polevaya S.A. Vegetative correlates of conscious representation of emotional stress. Sovremennye tehnologii v medicine 2013; 5(4): 69-77.

4. Fedotchev A.I. Stress, its consequence for a man and modern non-pharmaceutical approaches to their elimination. Uspekhi fiziologicheskikh nauk 2009; 40(1): 102-115.

5. Grigorieva V.N. Cognitive rehabilitation - a new direction of medical aid to patients with the brain focal lesions. Sovremennye tehnologii v medicine 2010; 2: 95-99.

6. Kaplan A.Ya., Kochetova A.G., Shishkin S.L., Basyul I.A., Ganin V.R., Vasilev A.N., Liburkina S.P. Experimental and theoretical foundations and practical implementation of technology brain-computer interface. Byulleten sibirskoy meditsiny 2013; 12(2): 21-29.
7. Wood G., Kober S.E., Witte M., Neuper C. On the need to better specify the concept of "control" in brain-computerinterfaces/neurofeedback research. Front Syst Neurosci 2014; 8: 171, http://dx.doi.org/10.3389/fnsys.2014.00171.

8. Huster R.J., Mokom Z.N., Enriquez-Geppert S., Herrmann C.S. Brain-computer interfaces for EEG neurofeedback: peculiarities and solutions. Int J Psychophysiol 2014; 91(1): 36-45, http://dx.doi.org/10.1016/j.ijpsycho.2013. 08.011.

9. Gruzelier J.H. EEG-neurofeedback for optimising performance. III: a review of methodological and theoretical considerations. Neurosci Biobehav Rev 2014; 44(2): 159-182, http://dx.doi.org/10.1016/j.neubiorev.2014.03.015.

10. Fedotchev A.I., Oh S.J., Semikin G.I. Combination of neurofeedback technique with music therapy for effective correction of stress-induced disorders. Sovremennye tehnologii $v$ medicine 2014; 6(3): 60-63.

11. Müller W., Haffelder G., Schlotmann A., Schaefers A.T., Teuchert-Noodt G. Amelioration of psychiatric symptoms through exposure to music individually adapted to brain rhythm disorders - a randomised clinical trial on the basis of fundamental research. Cogn Neuropsychiatry 2014; 19(5); 399413, http://dx.doi.org/10.1080/13546805.2013.879054.

12. Doskin V.A., Lavrent'eva N.A., Miroshnikov M.N., Sharay V.V. Test for differential self-assessment of functional state. Voprosy psikhologii 1973; 6: 141-145.

13. Grigorieva V.M., Tkhostov A.Sh. Sposob otsenki emotsional'nogo sostoyaniya cheloveka [Method for assessing human emotional state]. Patent RF 2291720 S1. 2007.

14. Fedotchev A.I., Bondar' A.T., Semenov V.S. Nelekarstvennaya korrektsiya funktsional'nykh rasstroystv u cheloveka. Printsip dvoynoy obratnoy svyazi ot EEG ostsillyatorov patsienta [Non-pharmaceutical correction of human functional disorders. The concept of double feedback from patient's EEG oscillators]. Saarbrucken: LAP Lamberts Academic Publishing; 2010.

15. Bazanova O.M., Vernon D. Interpreting EEG alpha activity. Neurosci Biobehav Rev 2014; 44: 94-110, http://dx.doi. org/10.1016/j.neubiorev.2013.05.007.

16. Koelsch S. Brain correlates of music-evoked emotions. Nat Rev Neurosci 2014; 15(3): 170-180, http://dx.doi. org/10.1038/nrn3666.

17. Volchek O.D. Znachenie muzyki i semantika ee zvukov [Significance of music and semantics of its sounds]. Moscow: Folium; 2014.

18. Radstaak M., Geurts S.A., Brosschot J.F., Kompier M.A. Music and psychophysiological recovery from stress. Psychosom Med 2014; 76(7): 529-537, http://dx.doi.org/10.1097/ PSY.0000000000000094.

19. Frederick J.A. Psychophysics of EEG alpha state discrimination. Conscious Cogn 2012; 21(3): 1345-1354, http:// dx.doi.org/10.1016/j.concog.2012.06.009.

20. Smith R., Rathcke T., Cummins F., Overy K., Scott S. Communicative rhythms in brain and behaviour. Philos Trans $R$ Soc Lond B Biol Sci 2014; 369(1658): 20130389, http://dx.doi. org/10.1098/rstb.2013.0389.

21. Alexeeva M.V., Muravlyova K.B., Sapina E.V., Bazanova O.M., Balioz N.V. Training for voluntarily increasing individual upper $\alpha$ power as a method for cognitive enhancement. Fiziologiya cheloveka 2012; 38(1): 51-60. 